\title{
Envelhecimento populacional e financiamento público: análise do Rio Grande do Sul utilizando um modelo multissetorial
}

\author{
Adelar Fochezatto* \\ Guilherme Correa Petry ${ }^{\star \star}$ \\ Jacó Braatz ${ }^{\star \star \star}$ \\ Paolo Mazzoncini Martinez $z^{\star \star \star *}$ \\ Mariana Ceia Ramos Mariano da Rocha ${ }^{\star \star \star \star *}$
}

\begin{abstract}
Os efeitos econômicos do envelhecimento populacional é um tema ainda pouco estudado em países em desenvolvimento. No contexto brasileiro, o Rio Grande do Sul é um dos estados com maiores taxas de envelhecimento populacional. Esta mudança demográfica altera o perfil do consumo da economia, influenciando outras variáveis relacionadas. 0 objetivo deste trabalho é analisar os impactos das mudanças demográficas na arrecadação de impostos sobre consumo no Rio Grande do Sul. Para isso, utilizou-se um modelo de insumo-produto regional. Os resultados mostram que o envelhecimento populacional gera um perfil de consumo que reduz a carga destes impostos na economia.
\end{abstract}

Palavras-chave: Envelhecimento populacional. Perfil do consumo. Modelo multissetorial. Impostos.

\footnotetext{
* Pontifícia Universidade Católica do Rio Grande do Sul (PUCRS), Porto Alegre-RS, Brasil (adelar@pucrs.br; http://orcid. org/0000-0001-7192-3986).

** Secretaria da Fazenda do Rio Grande do Sul (Sefaz/RS), Porto Alegre-RS, Brasil (guilhermecp@sefaz.rs.gov.br; https:// orcid.org/0000-0002-0523-9323).

*** Secretaria da Fazenda do Rio Grande do Sul (Sefaz/RS), Porto Alegre-RS, Brasil (jacob@sefaz.rs.gov.br; https://orcid. org/0000-0002-5040-7859).

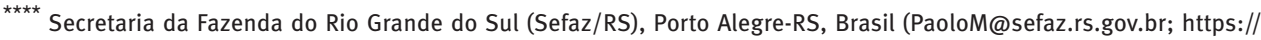
orcid.org/0000-0002-0271-8281).

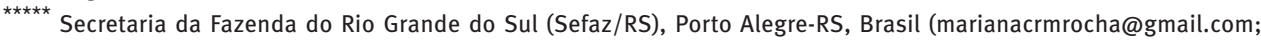
https://orcid.org/0000-0002-7958-5683).
} 


\section{Introdução}

O envelhecimento populacional é um processo demográfico decorrente de redução da taxa de natalidade, seguida de aumento na expectativa de vida da população. Ele ocorre quando a população idosa cresce a uma taxa maior do que a população jovem ${ }^{1}$ (ALMEIDA, 2002). Segundo Moreira e Carvalho (1992), o envelhecimento populacional é tanto maior quanto mais intensa é a queda dos níveis de fecundidade, sobretudo se estes ficam abaixo da taxa de reposição populacional. Dessa maneira, o fenômeno atinge países e classes sociais de formas diversas, com maior intensidade nas classes mais ricas da população, estando atualmente em estágios mais avançados em países desenvolvidos.

Desde a segunda metade do século passado, as altas taxas de crescimento econômico associadas a uma queda acentuada na fertilidade em países europeus e do Leste Asiático chamaram a atenção dos especialistas. Desde então, estudos tanto na literatura nacional quanto internacional, envolvendo análises empíricas e teóricas, têm sido recorrentes para verificar os impactos da variável demográfica no crescimento econômico (ROMERO, 2011).

Segundo Almeida (2002), no Brasil, o surgimento de trabalhos científicos sobre os impactos econômicos decorrentes do envelhecimento populacional ocorreu na transição da década de 1980 e início dos anos 1990. Sobretudo entre as décadas de 1970 e 1980, um declínio generalizado e consistente atingiu as taxas de fecundidade de todas as grandes regiões brasileiras (SIMÕES, 2016). A maior parte desses estudos, no entanto, não analisou o consumo das famílias no contexto de envelhecimento populacional, notadamente pela falta de dados sobre os orçamentos familiares (ALMEIDA, 2002).

Segundo Santiago (2014), um dos mecanismos pelos quais o envelhecimento populacional afeta a economia é por meio de mudanças nos padrões de consumo, dada a importância deste na composição da renda e da demanda final. Em função dos diferentes comportamentos econômicos dos indivíduos ao longo do ciclo da vida, o fenômeno demográfico ocasiona uma mudança na cesta de consumo das famílias, o que, por sua vez, tem o potencial de afetar a composição setorial de uma economia.

0 presente trabalho, portanto, insere-se na literatura voltada para o estudo dos impactos setoriais do envelhecimento populacional decorrentes das mudanças nos padrões de consumo. Por meio da análise desses efeitos setoriais, busca-se verificar em que medida as diferenças no comportamento do consumo em função da idade das pessoas afeta a arrecadação de impostos que incidem sobre o consumo. Assim, o objetivo geral deste trabalho é analisar os impactos do envelhecimento populacional sobre a arrecadação de ICMS no Rio Grande do Sul.

No caso do Rio Grande do Sul, seguindo a tendência nacional, o consumo das famílias representa importante componente da demanda da economia. Ainda, a estrutura da

\footnotetext{
${ }^{1}$ Embora não exista um limite mínimo global que defina o grupo de pessoas idosas, em estudos demográficos, costuma-se utilizar o parâmetro da Organização Mundial da Saúde, de 60 anos, também considerado na Política Nacional do Idoso (Lei n. 8.842, de 1994).
} 
pirâmide etária gaúcha (Gráfico 1), de base alargada, indica uma composição populacional majoritariamente de adultos, mas que, associada a uma taxa de fecundidade abaixo dos níveis de reposição populacional, tende ao envelhecimento populacional. De acordo com dados divulgados pela Fundação de Economia e Estatística (FEE, 2012), entre 2015 e 2050 , o número de idosos (65 anos ou mais) na população gaúcha vai quase duplicar, representando 2,24 milhões de pessoas.

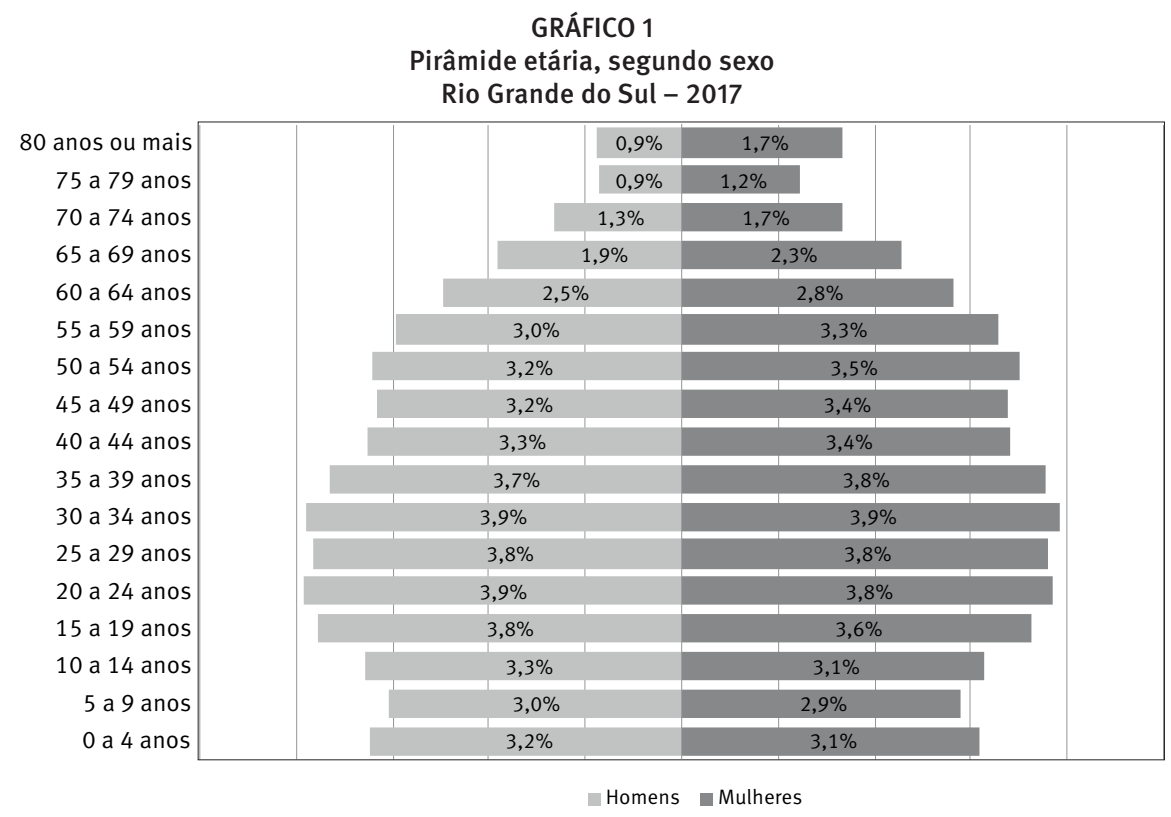

Fonte: Estimativas da Fundação de Economia e Estatística (FEE, 2012). Elaboração dos autores.

A escolha do Rio Grande do Sul deve-se não apenas por ser uma das principais unidades da federação em termos de participação no Produto Interno Bruto e na população total do Brasil - representa $6,4 \%$ e $5,4 \%$ dos totais nacionais, respectivamente -, mas também por apresentar uma transição demográfica em estágio relativamente mais avançado do que outros estados brasileiros.

Entre os Censos Demográficos de 2000 e 2010 do IBGE, o Rio Grande do Sul foi o estado que apresentou a menor taxa de crescimento populacional e uma das maiores expectativas de vida, e projeta-se que sua população começará a declinar a partir de 2025 (FEE, 2012). Para além do aumento esperado das despesas com saúde e de um grau de comprometimento ainda maior dos gastos com inativos, a expectativa é de que o fenômeno demográfico tenha influência também sobre as receitas estaduais, já que mais de $60 \%$ das receitas líquidas do estado derivam da arrecadação com o ICMS, imposto incidente sobre o consumo.

Portanto, para atingir o objetivo proposto, é realizada uma revisão bibliográfica do tema, apresentando as principais conclusões empíricas e teóricas comuns aos autores. Utiliza-se, ainda, um modelo de multiplicadores construído a partir da matriz de insumo-produto 
do Rio Grande do Sul, analisando o caso específico do estado, por meio da associação entre a estrutura setorial da produção com a estrutura setorial do consumo por faixas etárias e com a arrecadação de impostos sobre o consumo.

A seguir é feita uma breve revisão bibliográfica acerca do tema dinâmica demográfica e padrão de consumo, destacando as principais conclusões comuns aos casos empíricos estudados. Posteriormente apresentam-se os procedimentos metodológicos empregados e as adaptações realizadas para utilizar a matriz insumo-produto em conjunto com os dados da POF e as projeções populacionais do Rio Grande do Sul. São discutidos os principais resultados obtidos pela modelagem aplicada ao caso do estado, relacionando-os com a bibliografia estudada. Encerrando o artigo, são apresentadas as considerações finais e possíveis extensões do trabalho.

\section{Revisão bibliográfica}

O envelhecimento populacional é uma das consequências da transição demográfica de um país em que a diminuição da taxa de fecundidade é acompanhada por um aumento na expectativa de vida da população. Tal mudança na estrutura etária afeta a economia, pois o comportamento econômico dos indivíduos varia ao longo do ciclo de vida, em termos tanto de demanda (decisões de consumo e poupança) quanto de oferta (disponibilidade de mão de obra) (DENTON; SPENCER, 1999; LEE; MASON, 2010a; SANTIAGO, 2014).

Segundo Lee e Mason (2010b), ainda que o crescimento populacional implique um menor consumo per capita, o envelhecimento populacional pressupõe mais pessoas consumindo do que trabalhando. Nesse contexto, as transferências públicas e privadas teriam papel central no financiamento desse desequilíbrio, e o investimento em capital poderia até mesmo compensar o menor número relativo de trabalhadores em uma população. Portanto, os efeitos macroeconômicos do envelhecimento populacional variariam de país para país, de acordo com as políticas adotadas e o perfil da população.

A literatura disponível que trata das mudanças nos padrões de consumo no contexto de transição demográfica embasa-se notadamente em casos empíricos de países que passam pelo processo de envelhecimento populacional. Portanto, para fins do presente artigo, foram selecionadas referências, nacionais e internacionais, que analisam não apenas as alterações no consumo decorrentes da variável demográfica, mas também suas consequências na composição setorial da economia.

Utilizando um modelo de insumo-produto econométrico para a região de Chicago/EUA, Yoon e Hewings (2006) analisaram os impactos do envelhecimento populacional sobre a economia da região. 0 estudo também projetou mudanças na distribuição de renda como consequência indireta do processo demográfico, o que, segundo os autores, tem significativo impacto sobre os padrões de consumo das famílias.

Além de estimarem uma maior importância do consumo na economia da região, os autores previram que a mudança demográfica traria efeitos multiplicadores sobre a produção, 
que atingiriam os setores diferentemente, afetando a competitividade dos mesmos. Dentre as projeções, os setores cuja participação no consumo das famílias teve a maior queda foram os de vestuário e bebidas e fumo (YOON; HEWINGS, 2006).

Analisando o caso escocês, Dewhurst (2006) apontou que um maior número relativo de idosos aumentaria o consumo total da população, dado o crescimento de gastos relacionados à saúde. A partir de um modelo de insumo-produto, o autor analisou os impactos da transição demográfica nos diferentes setores produtivos no país. Segundo ele, diante das diferenças nos padrões de consumo de cada faixa etária e dos efeitos indiretos do envelhecimento populacional na economia, estima-se que serviços relacionados à saúde e energia apresentariam um aumento em sua demanda final, enquanto setores como educação e transportes teriam sua demanda final reduzida. No entanto, de acordo com o autor, não seria possível afirmar, com segurança, quais setores seriam mais beneficiados ou prejudicados.

O impacto da evolução do padrão do consumo associado ao envelhecimento populacional em Portugal foi analisado por Albuquerque e Lopes (2010), que, por meio de um modelo de insumo-produto, avaliaram os efeitos do envelhecimento populacional sobre produção setorial, importações, valor adicionado e emprego, identificando os setores que seriam favorecidos e aqueles prejudicados com a mudança demográfica. Os autores encontraram resultados que indicaram, por um lado, o aumento da produção bruta e das importações e, por outro, a diminuição do valor adicionado e do emprego.

Com relação à composição setorial, o estudo concluiu que os setores com trabalhadores de níveis de educação abaixo da média foram os mais beneficiados com o envelhecimento populacional, tais como instrumentos médicos, produtos químicos e farmacêuticos, serviços de saúde e produtos da agropecuária. Já os setores com trabalhadores de maior nível de instrução foram relativamente prejudicados, tais como administração pública, seguros e previdência, educação, veículos automotores, computadores e máquinas de escritório, serviços de recreação, cultura e esportes.

Utilizando um modelo de equilíbrio geral, Kluge et al. (2014) analisaram dados da população alemã para prever os efeitos sociais, ambientais e econômicos de uma população menor e mais envelhecida. Diferentemente da abordagem tradicional, que enfatiza o ônus do envelhecimento populacional, os autores concluíram que, no longo prazo, haveria vantagens econômicas, sociais e ambientais do processo de envelhecimento. Eles citaram como possíveis benefícios: diminuição da emissão de $\mathrm{CO}_{2}$; aumento da escolaridade (capital humano) e, portanto, da produtividade, da força de trabalho; e maiores transferências intergeracionais.

Ademais, os autores chamaram a atenção para os possíveis efeitos intergeracionais da mudança na estrutura etária no longo prazo, já que é esperado que a relação entre lazer, mercado de trabalho e trabalho doméstico se modifique. Como exemplo, eles mencionaram uma maior participação feminina no mercado de trabalho e um maior tempo destinado ao lazer pelos indivíduos, o que, finalmente, acabaria alterando os hábitos de consumo dos indivíduos de uma mesma faixa etária. 
Aigner-Walder (2015) investigou os efeitos potenciais do envelhecimento populacional no padrão de consumo na Áustria, estimando ainda as elasticidades de demanda e elasticidades de preço de demanda para cada faixa etária. Em um primeiro cenário, foram identificados setores beneficiados (de alimentação, saúde) e prejudicados (transportes, restaurantes, lazer) com a mudança demográfica. No entanto, ao se supor uma melhora na distribuição de renda, como efeito indireto do envelhecimento populacional, setores antes prejudicados, como transportes, acabaram apresentando o maior aumento relativo no seu consumo total. Portanto, seguindo o exemplo de Yoon e Hewings (2006), o caso austríaco estimou que mudanças na distribuição de renda da população são importantes variáveis para analisar efeitos demográficos na economia.

Para o caso brasileiro, Zanon et al. (2013) analisaram como o envelhecimento populacional pode afetar a estrutura produtiva do país, dadas as mudanças previstas no padrão de consumo da população no período 2005-2050. Para tanto, foi utilizado um modelo de insumo-produto e informações da Pesquisa de Orçamentos Familiares (POF) de 2008-2009, da Pesquisa Nacional por Amostra de Domicílios (PNAD) de 2005 e da população brasileira projetada para o período de 1980 a 2050. Ao analisarem a produção necessária para satisfazer o consumo das famílias nos anos analisados, os autores verificaram que os setores com maior crescimento devem ser aqueles que produzem produtos de maior consumo relativo por parte das famílias idosas, tais como indústria farmacêutica, saúde, mercantil, intermediação financeira e seguros, outros serviços, instrumentos médico-hospitalares e serviços imobiliários e aluguel. Por outro lado, os setores com menor crescimento da produção devem ser os de educação mercantil, vestuário, calçados e produtos do couro, serviços de alojamento e alimentação, produtos do fumo, veículos automotores, peças e equipamentos. Os autores apontaram, contudo, outros determinantes que poderiam promover mudanças no consumo privado dentre as faixas etárias ao longo do tempo, como mudanças em preferências, nível de renda, preço relativo dos bens e serviços, taxa de juros, renda esperada e riqueza.

Uma metodologia alternativa para desagregar o gasto em bens e serviços por grupos etários foi proposta por Santiago et al. (2013). Em primeiro lugar, estimaram-se as semielasticidades do efeito da idade sobre o gasto para 15 bens e serviços da POF, utilizando o modelo Tobit. Estas elasticidades foram usadas para transformar o vetor de consumo das famílias da matriz insumo-produto em um vetor desagregado por grupo etário. A hipótese de que a presença de idosos ou crianças na composição doméstica altera o consumo familiar foi corroborada pelos resultados, especialmente em bens e serviços relacionados à saúde.

Também para o caso brasileiro, o estudo de Santiago (2014) analisou as mudanças de longo prazo na estrutura produtiva e na composição setorial do país, decorrentes da alteração do padrão de consumo, por meio de um modelo de equilíbrio geral computável (EGC). Para isso, primeiramente, foi feita a desagregação do vetor de consumo por grupos etários, para então identificar todos os efeitos de encadeamentos entre os setores da economia. Diferentemente do método insumo-produto, os modelos de equilíbrio geral são mais flexíveis e adaptáveis, por exemplo, permitindo o uso de preços flexíveis. 
Os resultados das projeções indicaram um aumento na demanda por alguns produtos e serviços, sobretudo por serviços de saúde (medicamentos, atendimento hospitalar e planos de saúde), além de serviços prestados às famílias e consumo de energia; e uma redução em outros, principalmente nos setores de alimentação e educação (SANTIAGO, 2014).

De forma geral, os estudos empíricos aqui analisados permitiram a inferência de certas premissas com relação às mudanças no consumo que embasarão a análise final do presente trabalho. Em primeiro lugar, os trabalhos que consideraram o consumo de forma agregada concluíram que a importância do consumo na economia aumentaria como decorrência do envelhecimento populacional (DEWHURST, 2006; YOON; HEWINGS, 2007; LEE; MASON, 2010 b). Essa tese é comumente aceita dentre os especialistas e dialoga com o modelo de Modigliani, segundo o qual existe aumento das despesas de consumo ao longo do ciclo de vida das pessoas.

Em segundo lugar, e especialmente importante para o objetivo do presente artigo, diversos trabalhos chegaram a conclusões similares com relação às mudanças nas demandas dos setores produtivos como decorrência das alterações nos padrões de consumo. De maneira geral, os estudos indicaram que, com o envelhecimento populacional, setores mais relacionados à saúde, energia e alimentação apresentariam um aumento relativo em suas demandas, enquanto setores como vestuário, educação, transportes, alimentos, bebidas e fumo registrariam uma diminuição relativa em suas demandas finais (DEWHURST, 2006; YOON; HEWINGS, 2007; ALBUQUERQUE; LOPES, 2010; ZANON et al., 2011; SANTIAGO et al., 2013; SANTIAGO, 2014; AIGNER-WALDER, 2015).

$\mathrm{Na}$ linha dos trabalhos apresentados, o presente artigo analisará os impactos setoriais nas mudanças dos padrões de consumo decorrentes do envelhecimento populacional no Rio Grande do Sul, com o fim específico de verificar a influência dos mesmos na arrecadação tributária.

\section{Metodologia}

Para verificar a relação entre as mudanças na estrutura etária da população e a arrecadação de impostos indiretos no caso do Rio Grande do Sul, foi preciso associar a composição populacional com o padrão de consumo de cada faixa etária e verificar os possíveis efeitos de encadeamento na estrutura produtiva. Em termos mais específicos, buscou-se verificar: de que forma a estrutura etária da população determina o perfil do consumo da economia; como o perfil do consumo influencia a estrutura setorial de produção; e como os dois efeitos anteriores afetam a arrecadação de impostos.

Para buscar responder aos questionamentos propostos, utilizou-se a abordagem da matriz insumo-produto juntamente com a Pesquisa de Orçamentos Familiares (POF), já vista em Zanon et al. (2013), Santiago et al. (2013) e Santiago (2014). A matriz de insumo-produto inclui informações setoriais de valor da produção, valor adicionado, remuneração do trabalho e do capital, impostos incidentes sobre a produção e circulação de produtos 
e de diferentes componentes da demanda final. Além disso, ela contempla uma matriz de interligações produtivas (relações técnicas de insumo-produto) dos diferentes setores do sistema econômico. Esta poderosa ferramenta de análise econômica foi desenvolvida por Leontief (1941), sendo que a principal referência atual sobre a construção e uso de matrizes nacionais e regionais é Miller e Blair (2009).

0 modelo de insumo-produto é de uso bastante difundido na literatura, no entanto, apresenta várias limitações, como funções lineares, preços fixos e capacidade produtiva ilimitada. Já os modelos de equilíbrio geral permitem trabalhar com funções não lineares, mas possuem o inconveniente de serem intensivamente parametrizados, cujos valores dos parâmetros são calibrados ou usados valores já existentes em outros trabalhos. Há, portanto, um trade off nesta escolha: modelo com formas funcionais mais simples e de fácil interpretação dos parâmetros versus modelos mais flexíveis com parâmetros flexíveis e de obtenção muitas vezes duvidosa dos mesmos, dificultando a interpretação dos resultados. Neste trabalho optou-se pela primeira alternativa. Além disso, o modelo de insumo-produto é facilmente replicável para outros estados da federação.

A matriz de insumo-produto (MIP) é a ferramenta adequada para efetuar uma análise dos impactos da estrutura etária sobre a arrecadação tributária, pois interliga todos os componentes do sistema econômico. Ela fornece as relações intersetoriais e as informações detalhadas sobre a demanda final, o valor adicionado e os impostos indiretos por setor de atividade. Portanto, ela captura as interdependências entre os diversos setores institucionais, organizadas de maneira consistente, de modo a igualar receitas e despesas para cada um destes setores. Especificamente para o caso gaúcho, utilizou-se a matriz de insumo-produto do Rio Grande do Sul (MIP-RS) divulgada pela FEE. Esta matriz tem como ano base 2008 e contempla 37 setores e 65 produtos.

As linhas da matriz mostram a demanda total do produto de cada setor, a qual é igual à soma da demanda intermediária e da demanda final (equação 1). As colunas mostram que a produção bruta de cada setor é igual ao consumo intermediário mais os fatores primários ou valor adicionado (equação 2). Para cada setor da economia, a produção bruta (oferta total) é igual à demanda total (equação 3). Em termos agregados, a soma do valor adicionado dos setores fornece a renda agregada da economia e a soma da demanda final dos setores resulta no dispêndio agregado (equação 4). Em termos formais:

$$
\begin{aligned}
& X_{i}=\sum_{j=1}^{n} X_{i j}+\sum_{s=1}^{S} Y_{i s} \\
& X_{j}=\sum_{i=1}^{n} X_{i j}+\sum_{r=1}^{R} V_{r j} \\
& \sum_{j=1}^{n} X_{i j}+\sum_{s=1}^{S} Y_{i s}=\sum_{i=1}^{n} X_{i j}+\sum_{r=1}^{R} V_{r j} \\
& \sum_{i=1}^{n} \sum_{s=1}^{S} Y_{i s}=\sum_{j=1}^{n} \sum_{r=1}^{R} V_{r j}
\end{aligned}
$$


Onde: $X_{i}$ é a demanda total do produto do setor $i ; X_{i j}$ é a demanda intermediária do produto do setor $i$ por parte do setor $j ; Y_{i s}$ é a demanda final do produto do setor $i$ na categoria de demanda final $s ; X_{j}$ é a produção bruta do setor $j ; V_{r j}$ é o fator primário $r$ no valor adicionado do setor $j ; i, j=1,2, \ldots, n$ são os setores produtivos da economia; $s=1,2, \ldots, S$ são as categorias de demanda final; e $r=1,2, \ldots, R$ são os fatores primários que compõem 0 valor adicionado.

No modelo de insumo-produto, supõe-se que os coeficientes técnicos de produção sejam fixos e mostrem a quantidade do produto do setor $i$ requerida para produzir uma unidade de produto do setor $j$. Os requerimentos de fatores primários também têm uma relação fixa e definem a quantidade do fator primário $r$ requerida para produzir uma unidade de produto total no setor $j$. Assim:

$a_{i j}=\frac{X_{i j}}{X_{j}}$ ou

$a_{i j} X_{j}=X_{i j}$

$b_{r j}=\frac{V_{r j}}{X_{j}}$ ou

$b_{r j} X_{j}=V_{r j}$

Onde: $a_{i j}$ representa os coeficientes técnicos de produção; e $b_{r j}$ representa os coeficientes dos fatores primários.

0 modelo de impactos sobre a arrecadação de impostos sobre o consumo pode ser definido de forma similar ao dos fatores primários. Definindo $R$ como a arrecadação tributária e $z$ as diferentes categorias de tributos, os coeficientes de arrecadação podem ser obtidos da seguinte forma:

$t_{z j}=\frac{R_{z j}}{X_{j}}$ ou

$t_{z j} X_{j}=R_{z j}$

Onde: $t_{z j}$ representa os coeficientes de arrecadação tributária.

No modelo aberto de insumo-produto, todas as categorias de demanda final são consideradas exógenas. Partindo das equações (1) e (5) e usando a notação matricial, a solução desse modelo é definida pela seguinte expressão:

$X=(I-A)^{-1} Y$

Onde: $X$ é um vetor coluna $(n \times 1)$ de produção total dos setores; $I$ é uma matriz identidade $(n \times n)$; $A$ é a matriz de coeficientes técnicos de produção $(n \times n)$; e $Y$ é um vetor coluna ( $n$ $x$ 1), representando o somatório das categorias de demanda final para o produto de cada setor. Os coeficientes da matriz inversa $(I-A)^{-1}$ são chamados de requerimentos diretos e indiretos de produção.

Além dos requerimentos de produção, é possível definir os requerimentos de fatores primários e a arrecadação de tributos. Combinando as equações (6) e (7) na forma matricial 
com a equação (8), têm-se as seguintes expressões de demanda de fatores primários e de arrecadação fiscal:

$V=B X$ ou

$V=B(I-A)^{-1} Y$

$R=T X$ ou

$R=T(I-A)^{-1} Y$

Onde: $V$ é um vetor indicando a demanda de um determinado fator primário em cada setor econômico ( $n \times 1$ ); $B$ é uma matriz diagonal dos coeficientes de um determinado fator primário ( $n \times n)$; $R$ é um vetor indicando a arrecadação de um determinado tributo sobre cada setor econômico ( $n \times 1)$; e $T$ é uma matriz diagonal dos coeficientes de arrecadação tributária de um determinado tributo $(n \times n)$.

As mudanças do perfil dos gastos das famílias são obtidas em quatro etapas. Primeiro, utilizando a Pesquisa de Orçamentos Familiares (POF) de 2008-09, referente ao Rio Grande do Sul, são apurados os gastos por produtos e faixas etárias. Segundo, compatibilizam-se as informações dos produtos da POF com os setores da MIP-RS, o que foi feito, inicialmente, entre a POF (CNAE-Domiciliar) e a CNAE (Classificação Nacional de Atividades Econômicas) e, posteriormente, entre esta última e o SCN (Sistema de Contas Nacionais). Terceiro, utilizam-se as projeções populacionais por faixas etárias da Fundação de Economia e Estatística (FEE) para os anos de 2025 e 2050 (Tabela 1). Por fim, incorporam-se as estruturas etárias dessas projeções na população existente em 2008 (ano base da MIP-RS). Para incorporar as estruturas etárias das projeções populacionais na população de 2008 , usou-se a participação das faixas etárias das projeções para redistribuir a população de 2008 . No Apêndice (Tabelas 1 a 3) encontram-se os dados de consumo por setor e faixa etária resultantes da compatibilização da POF com a matriz de insumo-produto para os três períodos analisados.

TABELA 1

População e projeções populacionais, segundo faixas etárias Rio Grande do Sul - 2000-2050

\begin{tabular}{|c|c|c|c|c|c|c|c|c|c|c|c|c|}
\hline \multirow[b]{2}{*}{$\begin{array}{l}\text { Faixas } \\
\text { etárias }\end{array}$} & \multicolumn{2}{|c|}{2000} & \multicolumn{2}{|c|}{2008} & \multicolumn{2}{|c|}{2009} & \multicolumn{2}{|c|}{2010} & \multicolumn{2}{|c|}{2025} & \multicolumn{2}{|c|}{2050} \\
\hline & $\begin{array}{l}\text { Pop. } \\
\text { (em } \\
\text { mil) }\end{array}$ & $\%$ & $\begin{array}{l}\text { Pop. } \\
\text { (em } \\
\text { mil) }\end{array}$ & $\%$ & $\begin{array}{l}\text { Pop. } \\
\text { (em } \\
\text { mil) }\end{array}$ & $\%$ & $\begin{array}{l}\text { Pop. } \\
\text { (em } \\
\text { mil) }\end{array}$ & $\%$ & $\begin{array}{l}\text { Pop. } \\
\text { (em } \\
\text { mil) }\end{array}$ & $\%$ & $\begin{array}{l}\text { Pop. } \\
\text { (em } \\
\text { mil) }\end{array}$ & $\%$ \\
\hline 0-9 anos & 1.743 & 17,0 & 1.546 & 14 & 1.508 & 13,8 & 1.368 & 12,8 & 1.232 & 11,1 & 813 & 8,4 \\
\hline 10-19 anos & 1.879 & 18,4 & 1.785 & 16,4 & 1.779 & 16,2 & 1.738 & 16,2 & 1.296 & 11,7 & 919 & 9,5 \\
\hline 20-29 anos & 1.624 & 15,9 & 1.821 & 16,7 & 1.822 & 16,6 & 1.765 & 16,5 & 1.530 & 13,8 & 1.078 & 11,1 \\
\hline 30-39 anos & 1.599 & 15,7 & 1.562 & 14,3 & 1.574 & 14,4 & 1.553 & 14,5 & 1.675 & 15,1 & 1.217 & 12,5 \\
\hline 40-49 anos & 1.361 & 13,4 & 1.568 & 14,4 & 1.573 & 14,3 & 1.533 & 14,3 & 1.626 & 14,7 & 1.224 & 12,6 \\
\hline 50-59 anos & 918 & 9,0 & 1.237 & 11,3 & 1.272 & 11,6 & 1.278 & 11,9 & 1.395 & 12,6 & 1.503 & 15,5 \\
\hline 60-69 anos & 602 & 5,9 & 760 & 7,0 & 791 & 7,2 & 809 & 7,6 & 1.260 & 11,4 & 1.393 & 14,3 \\
\hline 70-79 anos & 335 & 3,3 & 434 & 4,0 & 447 & 4,1 & 449 & 4,2 & 748 & 6,8 & 961 & 9,9 \\
\hline $\begin{array}{l}80 \text { anos e } \\
\text { mais }\end{array}$ & 128 & 1,3 & 195 & 1,8 & 200 & 1,8 & 202 & 1,9 & 309 & 2,8 & 603 & 6,2 \\
\hline
\end{tabular}

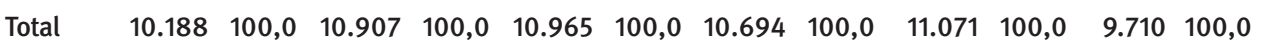

Fonte: Projeções populacionais. Fundação de Economia e Estatística. Elaboração dos autores. 
As mudanças na estrutura do consumo obtidas são utilizadas para a realização dos cenários. Elas representam os choques de demanda final da matriz de insumo-produto que, a partir dos seus multiplicadores setoriais de produção e dos coeficientes tributários setoriais, fornece os impactos sobre a arrecadação fiscal. Esses resultados serão confrontados com a arrecadação referente ao ano base.

0 vetor da demanda final em cada cenário muda apenas no componente consumo das famílias: no ano base, 2008 , o vetor é formado pela própria demanda final total presente na MIP-RS; e, nos cenários com as estruturas etárias de 2025 e 2050, os valores do ano base deste vetor são substituídos pelos valores de consumo setorial, considerando as novas estruturas etárias. Nos três casos, os vetores usados nas simulações representam o total da demanda final. Portanto, o que muda em cada cenário é a composição do consumo entre setores em função das diferentes estruturas etárias.

A operacionalização dos exercícios de impacto do envelhecimento seguiu a seguinte estratégia: para definir as diferenças de consumo por idade, foram utilizadas apenas as despesas individualizadas na POF. Assim, para os setores produtores de produtos com despesa individualizada na POF, o consumo foi distribuído entre as nove faixas etárias usando coeficientes específicos de cada faixa. No caso dos setores produtores de produtos com despesa coletiva na POF, o consumo foi distribuído entre as faixas etárias usando um coeficiente médio de consumo dado pela matriz de insumo-produto. Todas as simulações mantiveram a população total constante (a do ano base 2008), tendo sido alteradas apenas as composições etárias da população, advindas das projeções populacionais. Esta estratégia é um pouco diferente das encontradas na literatura. A mais próxima é a que foi empregada por Zanon et al. (2013), que usaram a PNAD para classificar os domicílios em dois grupos: idosos, quando mais de $50 \%$ dos moradores tinham 60 anos ou mais; e em domicílios não idosos, no caso de a proporção de idosos ser inferior a 50\%. Os exercícios de análise dos impactos do envelhecimento foram feitos considerando estes dois grupos.

O que diferencia este trabalho, portanto, é a sua aplicação a uma economia subnacional e por considerar uma desagregação maior em termos de faixas etárias da população. Esta aplicação se justifica pelo foco nos impactos de mudanças no padrão de consumo, decorrentes do envelhecimento populacional, sobre a arrecadação de impostos. Sabe-se que a arrecadação de impostos das esferas estaduais é concentrada em impostos sobre o consumo. Assim, seus resultados permitem antecipar algumas dificuldades financeiras das esferas subnacionais, uma vez que o processo de envelhecimento, em maior ou menor grau, está acontecendo em todas as unidades da federação. A relevância de se estudar o caso específico do Rio Grande do Sul é que se trata de uma das unidades da federação mais adiantadas na transição demográfica, com acelerado processo de envelhecimento e com reconhecidas dificuldades financeiras.

Esta estratégia metodológica não é a ideal. Primeiro, porque ela não considera as diferenças de consumo entre classes de renda. Pelas informações da POF, seria possível 
definir coeficientes de consumo para diferentes níveis de renda. No entanto, incluir esta classificação em conjunto com as faixas etárias poderia tornar as amostras muito pequenas, pelo menos nas faixas extremas. Segundo, porque tal estratégia considera que o padrão de consumo por faixa etária não muda ao longo do tempo. No entanto, reconhece-se que é muito difícil incorporar a dinâmica intertemporal. Conforme Wakabayashi e Hewings (2007), mudanças nos perfis de consumo geracionais são de difícil mensuração, pois exigem dados em um horizonte maior de tempo. Também não está no escopo deste estudo abordar o impacto de reformas previdenciárias, como o adiamento da aposentadoria, ou trabalhistas no padrão de consumo dos indivíduos. A influência da aposentadoria e dos salários nas decisões de consumo e nas elasticidades dos bens consumidos é analisada em Paulin e Duly (2002).

\section{Análise dos resultados}

Na presente seção, são analisados os resultados obtidos para verificar o impacto do envelhecimento populacional na arrecadação tributária para o caso gaúcho. Primeiramente, os resultados são abordados estritamente à luz das simulações realizadas. Em seguida, os dados quantitativos observados são relacionados com as principais conclusões obtidas na revisão bibliográfica.

Como esperado, a composição das despesas de consumo muda conforme a idade das pessoas. 0 Quadro 1 mostra os três principais produtos consumidos em cada faixa etária de acordo com a POF. Em linhas gerais, pode-se destacar os seguintes pontos: a participação relativa das despesas na área da educação foi significativa apenas na faixa etária de 20 a 29 anos, não estando entre os três principais produtos consumidos em nenhuma outra faixa; nas faixas etárias intermediárias, predominaram as despesas com aquisição de imóveis e veículos; e nas faixas etárias iniciais e finais, a participação relativa das despesas com produtos e serviços relacionados com a área da saúde foi relativamente maior. 0 perfil das despesas com saúde, no entanto, é um pouco diferente nesses dois estratos da população: enquanto nas faixas iniciais predominam despesas com assistência à saúde, nas faixas de população mais idosa aumentam relativamente as despesas com hospitalização e remédios (primeira e penúltima linhas do Quadro 1).

A Tabela 2 mostra a distribuição das despesas agregadas de consumo por faixas etárias. Estas informações resultam da combinação das despesas individualizadas da POF por faixas etárias e do vetor de consumo da matriz de insumo-produto do ano base 2008. A tabela apresenta também as despesas totais de consumo para diferentes estruturas etárias projetadas para 2025 e 2050, mantendo a população total do ano base (2008). As últimas quatro colunas mostram as diferenças nas despesas de consumo por faixas etárias em relação ao ano base (2008). 
QUADRO 1

Principais produtos consumidos, segundo faixas etárias Rio Grande do Sul - 2008/2009

\begin{tabular}{|l|ccc|}
\hline \multirow{2}{*}{ Faixas etárias } & \multicolumn{3}{|c|}{ Principais produtos } \\
\cline { 2 - 4 } & Primeiro & Segundo & Terceiro \\
\hline 10-19 anos & Outras (assistência à saúde) & Cursos regulares & Gasolina veículo próprio \\
20-29 anos & Outras (assistência à saúde) & Aquisição de veículos & Curso superior (educação) \\
$30-39$ anos & Outras (assistência à saúde) & Imóvel (aquisição) & Aquisição de veículos \\
40-49 anos & Imóvel (aquisição) & Outras (assistência à saúde) & Aquisição de veículos \\
$50-59$ anos & Imóvel (aquisição) & Outras (assistência à saúde) & Aquisição de veículos \\
60-69 anos & Imóvel (aquisição) & Aquisição de veículos & Outras (assistência à saúde) \\
$70-79$ anos & Outras (assistência à saúde) & Previdência privada & Aquisição de veículos \\
80 anos e mais & Hospitalização & Remédios & Aquisição de veículos \\
Todas & Imóvel (aquisição) & Outras (assistência à saúde) & Aquisição de veículos \\
\hline
\end{tabular}

Fonte: IBGE. Pesquisa de Orçamentos Familiares (POF) 2008/2009. Elaboração dos autores,

Nota: A POF não possui informações sobre despesas de consumo para pessoas na faixa etária de 0 a 9 anos. Os nomes dos produtos foram preservados conforme aparecem na POF. Para este ordenamento, foram desconsideradas despesas que não permitem identificar com precisão o produto em questão (ex. outras despesas correntes e empréstimos); a lista completa de produtos da POF com despesas individualizadas considerados neste estudo contempla 68 itens.

TABELA 2

Despesas de consumo e variação, segundo faixas etárias Rio Grande do Sul - 2008-2050 (1)

\begin{tabular}{|c|c|c|c|c|c|c|c|}
\hline \multirow{2}{*}{ Faixas etárias } & \multicolumn{3}{|c|}{ Despesas de consumo ( $\mathrm{R} \$$ milhões) } & \multicolumn{2}{|c|}{ Diferença E-08/25 } & \multicolumn{2}{|c|}{ Diferença E-08/50 } \\
\hline & $E-2008$ & E-2025 & $\mathrm{E}-2050$ & $\mathrm{R} \$$ milhões & $\%$ & R\$ milhões & $\%$ \\
\hline 10-19 anos & $13.336,6$ & $12.001,9$ & $11.359,1$ & $-1.334,70$ & $-10,0$ & $-1.977,50$ & $-14,8$ \\
\hline 20-29 anos & $16.109,0$ & $14.720,5$ & $13.505,7$ & $-1.388,50$ & $-8,6$ & $-2.603,30$ & $-16,2$ \\
\hline 30-39 anos & $16.480,7$ & $16.657,3$ & $14.932,9$ & 176,60 & 1,1 & $-1.547,80$ & $-9,4$ \\
\hline 40-49 anos & $18.058,4$ & $17.924,2$ & $16.244,4$ & $-134,20$ & $-0,7$ & $-1.814,00$ & $-10,0$ \\
\hline 50-59 anos & $19.018,8$ & $19.946,7$ & $22.568,0$ & 927,90 & 4,9 & $3.549,20$ & 18,7 \\
\hline 60-69 anos & $14.132,0$ & $20.091,0$ & $23.705,0$ & $5.959,00$ & 42,2 & $9.573,00$ & 67,7 \\
\hline 70-79 anos & $12.671,8$ & $19.384,0$ & $26.613,2$ & $6.712,20$ & 53,0 & $13.941,40$ & 110,0 \\
\hline 80 anos e mais & $6.229,1$ & $8.920,0$ & $18.089,1$ & $2.690,90$ & 43,2 & $11.860,00$ & 190,4 \\
\hline Todas & $116.036,9$ & $129.645,5$ & $147.018,1$ & $13.608,60$ & 11,7 & $30.981,20$ & 26,7 \\
\hline
\end{tabular}

Fonte: IBGE. Pesquisa de Orçamentos Familiares (POF) 2008/2009, MIP-RS 2008 e projeções populacionais da FEE. Elaboração dos autores.

(1) Foram consideradas as estruturas etárias de 2008, 2025 e 2050 e a população de 2008.

Nota: E-2008 indica estrutura etária de 2008; E-2025 indica estrutura etária de 2025; E-2050 indica estrutura etária de 2050;

E-08/25 indica a diferença entre as estruturas etárias de 2008 e 2025; e E-08/50 indica a diferença entre as estruturas etárias de 2008 e 2050. A POF não possui informações sobre despesas de consumo para pessoas na faixa etária de 0 a 9 anos.

A última linha da Tabela 2 mostra que a simples mudança de estrutura etária, mantendo a população total e o padrão de consumo constantes ao nível de 2008, aumenta a despesa total de consumo. No entanto, esse crescimento não é linear, pois, se considerarmos o número de anos em cada intervalo, o aumento verificado com a estrutura etária de 2050 é proporcionalmente menor do que o de 2025. No Apêndice (Tabelas 1 a 3), estas informações estão desagregadas para todos os setores da MIP-RS.

A Tabela 3 mostra os impactos diretos e indiretos do envelhecimento populacional sobre a arrecadação de ICMS em setores selecionados da MIP-RS. Estes resultados representam 
os impactos decorrentes das mudanças de estruturas etárias projetadas para 2025 e 2050, mantendo a população constante do ano base (2008). As variações são calculadas em relação a este ano base. No Apêndice (Tabela 4), estão os impactos sobre todos os setores da matriz.

Como salientado na metodologia, uma parte das despesas de consumo da POF é contabilizada apenas para domicílios e não para pessoas. Sendo assim, para esses produtos, não foi possível especificar as despesas por faixas etárias, tendo sido utilizado um coeficiente de consumo médio para todas as faixas. Portanto, os setores da MIP-RS que não possuem dados de despesas de consumo individualizadas na POF serão impactados apenas de forma indireta pelo envelhecimento populacional.

TABELA 3

Variação da arrecadação de ICMS, por estruturas etárias, segundo setores produtivos selecionados Rio Grande do Sul - 2008/2050 (1)

Em porcentagem

\begin{tabular}{lcc}
\hline \multicolumn{1}{c}{ Setores } & E-08/25 & E-08/50 \\
\hline Setores mais impactados & 13,06 & 29,15 \\
Atividades imobiliárias e aluguéis & 12,63 & 26,48 \\
Intermediação financeira, seguros e previdência complementar e serviços relacionados & 10,28 & 22,89 \\
Serviços de alojamento e alimentação & 7,09 & 21,64 \\
Têxteis, artefatos do vestuário e do couro, acessórios e calçados & 7,03 & 20,20 \\
Móveis e produtos das indústrias diversas & 9,47 & 19,93 \\
Serviços de informação & 9,68 & 18,74 \\
Serviços prestados às famílias e associativa & 0,26 & 0,55 \\
Setores menos impactados & 0,14 & 0,30 \\
Outros equipamentos de transporte & 0,09 & 0,19 \\
Material eletrônico e equipamentos de comunicações & 0,08 & 0,18 \\
Aparelhos/instrumentos médico-hospitalar, medida e óptico & 0,07 & 0,17 \\
Administração, saúde e educação públicas e seguridade social & 0,06 & 0,12 \\
Máquinas e equipamentos, inclusive manutenção e reparos & 0,01 & 0,02 \\
Outros serviços & $\mathbf{3 , 8 4}$ \\
Eletrodomésticos & $\mathbf{8 , 7 8}$ \\
Total dos setores & \\
\hline
\end{tabular}

Fonte: IBGE. Pesquisa de Orçamentos Familiares (POF) 2008/09, MIP-RS 2008 e Projeções Populacionais da FEE. Elaboração dos autores.

(1) Foram consideradas as estruturas etárias de 2008, 2025 e 2050 e a população de 2008.

Nota: E-08/25 indica a diferença entre as estruturas etárias de 2008 e 2025; e E-08/50 indica a diferença entre as estruturas etárias de 2008 e 2050.

Um dos resultados interessantes da Tabela 3 é o impacto global sobre a arrecadação, que foi um aumento de $3,8 \%$ com a estrutura etária de 2025 e de $8,8 \%$ com a de 2050 , ambas em relação a 2008. Considerando o número de anos entre o ano base e cada estrutura etária analisada, pode-se dizer que o crescimento da arrecadação é de aproximadamente 0,22 ponto percentual por ano no primeiro cenário e 0,20 no segundo. Na comparação setorial, deve-se ter em mente que alguns setores não têm variação de gastos em função das faixas etárias. Nestes casos, como já foi explicado, o coeficiente de consumo é igual 
para todas as faixas e, por isso, tais setores não se beneficiam diretamente do envelhecimento populacional. Feita esta ressalva, a Tabela 3 mostra que, entre os setores mais impactados pela alteração da estrutura etária, estão atividades imobiliárias e aluguéis; intermediação financeira, seguros e previdência complementar e serviços relacionados; e serviços de alojamento e alimentação. Por outro lado, entre os menos impactados, encontram-se máquinas e equipamentos, inclusive manutenção e reparos; outros serviços; e eletrodomésticos.

A Tabela 4 apresenta, de forma resumida, os impactos diretos e indiretos das mudanças na estrutura etária da população sobre o valor bruto da produção, valor adicionado, ICMS e emprego. Estes resultados mostram que o valor adicionado aumenta mais do que o valor bruto da produção, o emprego e o ICMS.

TABELA 4

Impactos das mudanças na estrutura etária da população sobre o valor bruto da produção, valor adicionado, ICMS e emprego Rio Grande do Sul - 2008-2050

\begin{tabular}{|c|c|c|c|c|c|}
\hline \multirow{2}{*}{ Especificação } & \multirow{2}{*}{$E-2008$} & \multirow{2}{*}{$E-2025$} & \multirow{2}{*}{$E-2050$} & \multicolumn{2}{|c|}{ Variação (\%) } \\
\hline & & & & $E-08 / 25$ & $E-08 / 50$ \\
\hline Valor bruto da produção (R\$ bilhões/ano) & 517.834 & 537.713 & 563.281 & 3,84 & 8,78 \\
\hline Valor adicionado (R\$ bilhões/ano) & 198.218 & 206.657 & 217.155 & 4,26 & 9,55 \\
\hline Emprego (unidades) & 7.015 .036 & 7.221 .880 & 7.505 .790 & 2,95 & 7,00 \\
\hline ICMS (R\$ bilhões/ano) & 33.339 & 34.144 & 35.235 & 2,41 & 5,69 \\
\hline Valor adicionado/valor bruto da produção (\%) & 38,28 & 38,43 & 38,55 & 0,40 & 0,71 \\
\hline $\begin{array}{l}\text { Valor bruto da produção/emprego ( } \mathrm{R} \$ \mathrm{mil} / \mathrm{ano} / \\
\text { empregado) }\end{array}$ & 73.818 & 74.456 & 75.046 & 0,86 & 1,66 \\
\hline $\begin{array}{l}\text { Valor adicionado/emprego (R\$ mil/ano/ } \\
\text { empregado) }\end{array}$ & 28.256 & 28.615 & 28.932 & 1,27 & 2,39 \\
\hline ICMS/valor adicionado (\%) & 16,82 & 16,52 & 16,23 & $-1,77$ & $-3,53$ \\
\hline ICMS/valor bruto da produção (\%) & 0,06 & 0,06 & 0,06 & $-1,37$ & $-2,84$ \\
\hline Valor adicionado/população (R\$/ano) & $18.173,54$ & $18.947,26$ & $19.909,77$ & 4,26 & 9,55 \\
\hline Emprego/população (\%) & 64,32 & 66,21 & 68,82 & 2,95 & 7,00 \\
\hline ICMS/população (R\$/ano) & $3.056,67$ & $3.130,48$ & $3.230,51$ & 2,41 & 5,69 \\
\hline
\end{tabular}

Fonte: Fundação de Economia e Estatística. Matriz de Insumo-Produto. Elaboração dos autores.

Duas questões relevantes emergem desses resultados. Primeiro, o menor crescimento do emprego, relativamente ao valor da produção e ao valor adicionado, reflete a mudança no mercado de trabalho resultante do envelhecimento populacional. Mantido o montante de capital na economia, uma redução relativa da População em Idade Ativa (PIA), que engloba os indivíduos aptos a trabalhar, tende a diminuir o número de indivíduos economicamente ativos - e, consequentemente, a aumentar a relação capital-trabalho disponível no mercado. Isso tende a favorecer os setores relativamente mais intensivos em capital e/ou que demandam menos trabalho. Com efeito, nos dois cenários analisados, o valor bruto da produção por empregado aumentou 0,86\% e 1,66\%, respectivamente. Esse resultado poderia indicar uma compensação da redução na mão de obra disponível por um incremento de produtividade, como previsto por Lee e Mason (2010b). 
A segunda questão relevante refere-se ao comportamento do ICMS. Seguindo a lógica previamente apresentada, esperar-se-ia um crescimento na arrecadação de tributos incidentes sobre o consumo, já que este aumentaria ao longo do ciclo de vida do indivíduo. No entanto, como ocorreu com o emprego, o ICMS também cresceu relativamente menos do que o valor adicionado e o valor bruto da produção. A carga tributária (ICMS/valor adicionado) cairia $1,77 \%$ e $3,53 \%$, respectivamente, nos cenários com estrutura etária de 2025 e de 2050.

Esse resultado pode ser explicado, por um lado, pelas diferenças nas preferências de consumo ao longo da vida, detalhadas anteriormente, e, por outro, pelo caráter seletivo do ICMS, com diferentes alíquotas entre os setores. Muitos dos setores que apresentaram aumento na demanda com o processo de envelhecimento populacional, como intermediação financeira, móveis e têxteis e vestuário, não são representativos na arrecadação de ICMS para o estado. Ainda, muitos setores que mostraram maior crescimento na demanda decorrente da mudança etária - como têxtil, calçadista e combustíveis derivados do petróleo e gás -, não obstante representarem a maior fonte de arrecadação do tributo para o Rio Grande do Sul, são alvo de diferentes programas de isenção e redução de alíquotas. Portanto, espera-se que o montante arrecadado com esses setores seja relativamente inferior ao incremento de consumo dos mesmos. Com isso, mantido todo o resto constante, pode-se afirmar, à luz dos resultados obtidos, que a carga tributária do ICMS na economia do estado tende a diminuir com o aumento do envelhecimento populacional.

\section{Comentários finais}

O objetivo geral deste trabalho foi analisar os impactos das mudanças na estrutura etária da população sobre a arrecadação tributária estadual (ICMS) via variação nos padrões de consumo. Os resultados encontrados permitem afirmar que o envelhecimento populacional altera a estrutura produtiva da economia, principalmente, em favor de setores relacionados com a área da saúde. Por outro lado, setores ligados à área da educação tendem a diminuir relativamente sua importância. Setores de bens duráveis, como a aquisição de veículos e imóveis, são relativamente mais relevantes nas faixas etárias intermediárias.

Em termos gerais, os resultados obtidos permitem inferir que a mudança do consumo, decorrente do envelhecimento populacional, tende a alterar a estrutura produtiva da economia em favor de setores com alto valor adicionado, alta produtividade (baixo impacto sobre o emprego) e com fortes interligações setoriais (altos impactos sobre a produção e o valor adicionado). Estes resultados consideram inalteradas as condições relacionadas a outras variáveis econômicas que poderiam influenciar o comportamento econômico dos indivíduos, como renda, preços relativos, taxa de juros, ou mesmo o efeito de reformas estruturais, como o adiamento de aposentadorias.

Quanto aos impactos do envelhecimento populacional sobre as receitas de ICMS, observou-se que estas aumentam, mas proporcionalmente menos do que o valor adicionado e 0 
valor bruto da produção. Esses resultados permitem inferir que os segmentos produtivos mais beneficiados com o envelhecimento são relativamente menos tributados pelo ICMS. Em outros termos, pode-se afirmar que, mantido todo o resto constante, a carga tributária do ICMS na economia do Rio Grande do Sul tende a diminuir com o envelhecimento populacional.

Estes resultados devem ser motivo de preocupação por parte do setor público, já que o envelhecimento populacional no Rio Grande do Sul anda em ritmo mais acelerado do que nos outros estados brasileiros. A problemática tende a ser ainda mais preocupante se forem considerados os possíveis efeitos do envelhecimento sobre as despesas públicas estaduais. As evidências empíricas, baseadas em outros estudos sobre o tema e nos dados da POF, são de que as despesas deverão aumentar no futuro, especialmente aquelas relacionadas com as áreas da saúde e previdência dos servidores públicos (WONG; CARVALHO, 2006; QUEIROZ; FIGOLI, 2011; CARNEIRO et al., 2013; MILLER; CASTANHEIRA, 2013; BONATTO, 2014).

Uma limitação importante deste estudo é a manutenção do padrão de consumo de 2008 nas simulações de efeitos das alterações nas estruturas etárias. Por isso, seus resultados não devem ser vistos como estimativas quantitativas exatas quanto à perda de arrecadação tributária do Estado. Sua validade está em mostrar evidências sobre os possíveis impactos do envelhecimento populacional na estrutura econômica estadual, que demandam a ação preventiva do setor público para adaptar-se a essa nova realidade iminente.

Em trabalhos futuros, o estudo pode ser estendido em várias direções. Uma possibilidade é decompor os impactos do envelhecimento sobre a arrecadação estadual em efeitos de mudanças de composição etária da população e efeitos de mudanças no tamanho da população. Também é possível analisar os impactos de despesas públicas, desagregadas por função dos gastos. Por fim, pode-se analisar possíveis impactos de diferentes opções de políticas públicas que visam aumentar a arrecadação tributária ou reduzir gastos.

\section{Referências}

AIGNER-WALDER, B. Effects of the demographic changes on private consumption: an almost ideal demand system analysis for Austria. Journal of Economic and Social Studies, v. 5, n. 1, p. 33-57, 2015.

ALBUQUERQUE, P. C.; LOPES, J. C. Economic impacts of ageing: an inter-industry approach. International Journal of Social Economics, v. 37, n. 12, p. 970-986, 2010.

ALMEIDA, A. N. Determinantes do consumo de famílias com idosos e sem idosos com base na Pesquisa de Orçamentos Familiares 1995/96. 2002. Dissertação (Mestrado em Ciências) Escola Superior de Agricultura “Luiz de Queiroz”, Universidade de São Paulo, Piracicaba, 2002.

BONATTO, T. V. Impacto do envelhecimento da população sobre os gastos públicos do Estado do Rio Grande do Sul. Trabalho de Conclusão do Curso (Extensão em Economia e Gestão Pública Contemporâneas) - Centro de Estudos e Pesquisas em Administração, Universidade Federal do Rio Grande do Sul, Porto Alegre, 2014. 
CARNEIRO, L. A. F.; CAMPINO, A. C. C.; LEITE, F.; RODRIGUES, C. G.; SANTOS, G. M. M.; SILVA, A. R. A. Envelhecimento populacional e os desafios para o sistema de saúde brasileiro. São Paulo: Instituto de Estudos de Saúde Suplementar, 2013. Disponivel em: http://www.iess.org. br/envelhecimentopop2013.pdf. Acesso em: 24 maio 2019.

DENTON, F.; SPENCER, B. Population aging and its economic costs: a survey of the issues and evidence. Hamilton: Research Institute for Quantitative Studies in Economics and Population, McMaster University, 1999. (QSEP Research Report, n. 340).

DEWHURST, J. H. L. Estimating the effect of projected household composition change on production in Scotland. Dundee: Department of Economic Studies, University of Dundee, 2006. (Working Paper, n. 186).

FOCHEZATTO, A. Estrutura da demanda final e distribuição de renda no Brasil: uma abordagem multissetorial utilizando uma matriz de contabilidade social. Economia, v. 12, p. 111-130, 2011.

FOCHEZATTO, A.; SILVA, C. E. L. Impactos da alteração de perfil do consumo das famílias sobre o emprego por ocupação e nível de qualificação: aplicação de um modelo multissetorial para o Brasil. Economia Aplicada, v. 19, n. 1, p.109-129, 2015.

FEE - Fundação de Economia e Estatística. Projeções populacionais para o Estado do Rio Grande do Sul: 2015-2050. Porto Alegre, 2012. Disponível em: https://arquivofee.rs.gov.br/ indicadores/populacao/projecoes-populacionais/projecoes-populacionais-antigas/. Acesso em: 10 abr. 2020.

IBGE Instituto Brasileiro de Geografia e Estatística. Pesquisa de Orçamentos Familiares 2008/2009. Rio de Janeiro, 2010. Disponível em: www.ibge.gov.br. Acesso em: 10 abr. 2020.

KLUGE, F.; ZAGHENI, E.; LOICHINGER, E.; VOGT, T. The advantages of demographic change after the wave: fewer and older, but healthier, greener, and more productive? PloS One, v. 9, n. 9, 2014.

LEE, R.; MASON, A. O envelhecimento da população e a economia geracional: principais resultados. Santiago do Chile: Cepal, 2010a. (Coleção Documentos de Projetos).

LEE, R.; MASON, A. Some macroeconomic aspects of global population aging. Demography, v. 47, p. 151-172, 2010 b.

LEONTIEF, W. The structure of the American economy, 1919-1929. Cambridge: Harvard University Press, 1941.

MILLER, R. E.; BLAIR, P. D. Input-output analysis: fundations and extensions. New York: Cambridge University Press, 2009.

MILLER, T.; CASTANHEIRA, H. C. The fiscal impact of population aging in Brazil: 2005- 2050. Revista Brasileira de Estudos de População, v. 30, supl., p. S5-S23, 2013.

MOREIRA, M. M.; CARVALHO, J. A. M. Envelhecimento da população e aposentadoria por idade. In: VIII ENCONTRO NACIONAL DE ESTUDOS POPULACIONAIS. Anais [...]. Brasília: Abep, 1992.

PAULIN, G.; DULY, A. Planning ahead: consumer expenditure patterns in retirement. Monthly Labor Review, p. 38-58, July 2002.

QUEIROZ, B. L.; FIGOLI, M. G. B. Population aging and the rising costs of public pension in Brazil. Belo Horizonte: Cedeplar/UFMG, 2011. (Texto para Discussão, n. 438).

RIO GRANDE DO SUL. Secretaria do Planejamento, Gestão e Participação Cidadã; FEE - Fundação de Economia e Estatística. Matriz de insumo-produto para o Rio Grande do Sul. Porto Alegre, 2014. Disponível em: https://arquivofee.rs.gov.br/wp-content/uploads/2014/11/20141120miprs. pdf. Acesso em: 01 ago. 2020. 
ROMERO, M. S. The role of demography on per capita output growth and saving rates. Rostock, Germany: Max Planck Institute for Demographic Research, 2011. (MPIDR Working Papers WP-2011-015).

SANTIAGO. F. S. Projeções dos impactos econômicos decorrentes das mudanças demográficas no Brasil para o período de 2010 a 2050. Tese (Doutorado em Economia) - Cedeplar/UFMG, Belo Horizonte, 2014.

SANTIAGO, F. S.; DOMINGUES, E. P.; ANDRADE, M. V. Transição demográfica e demanda por bens e serviços por grupo etário no Brasil. In: XLI ENCONTRO DA NACIONAL DE ECONOMIA. Anais [...]. Foz do Iguaçu/PR: Anpec, 2013.

SIMÕES, C. C. S. Relações entre as alterações históricas na dinâmica demográfica brasileira e os impactos decorrentes do processo de envelhecimento da população. Rio de Janeiro: IBGE, Coordenação de População e Indicadores Sociais, 2016. Disponível em: http://biblioteca.ibge. gov.br/biblioteca-catalogo?id=298579\&view=detalhes. Acesso em: 20 jul. 2020.

WAKABAYASHI, M.; HEWINGS. G. J. D. Life-cycle changes in consumption behavior: age-specific and regional variations. Journal of Regional Science, v. 47, n. 2, p. 315-337, 2007.

WONG, L. R.; CARVALHO, J. A. O rápido processo de envelhecimento populacional do Brasil: sérios desafios para as políticas públicas. Revista Brasileira de Estudos de População, v. 23, n. 1, p. 5-26, jan./jun. 2006.

YOON, S.; HEWINGS, G. J. D. Impacts of demographic changes in the Chicago region. Urbana, IL: Regional Economics Applications Laboratory, University of Illinois at Urbana-Champaign, 2006. (REAL Discussion Paper 06-T-7).

ZANON, R. R.; MORETTO, A. C.; RODRIGUES, R. L. Envelhecimento populacional e mudanças no padrão de consumo e na estrutura produtiva brasileira. Revista Brasileira de Estudos de População, v. 30, supl., p. S45-S67, 2013.

\title{
Sobre os autores
}

Adelar Fochezatto é doutor em Economia. Professor titular da Pontifícia Universidade Católica do Rio Grande do Sul (PUCRS). Pesquisador do Conselho Nacional de Desenvolvimento Científico e Tecnológico (CNPq).

Guilherme Correa Petryé doutorando no Programa de Pós-Graduação em Economia da Pontifícia Universidade Católica do Rio Grande do Sul (PPGE/PUCRS). Auditor-fiscal da Receita Estadual (Sefaz/RS).

Jacó Braatz é doutor em Economia do Desenvolvimento pelo Programa de Pós-Graduação em Economia da Pontifícia Universidade Católica do Rio Grande do Sul (PPGE/PUCRS). Auditor-fiscal da Receita Estadual (Sefaz/RS).

Paolo Mazzoncini Martinez é graduado em Gestão Estratégica das Organizações. Auditor-fiscal da Receita Estadual (Sefaz/RS).

Mariana Ceia Ramos Mariano da Rocha é graduanda em Economia na Universidade Federal do Rio Grande do Sul (UFRGS). Estagiária da Receita Estadual (Sefaz/RS).

\section{Endereço para correspondência}

\author{
Adelar Fochezatto \\ Av. Neusa Brizola, 600/206 \\ 90460-230 - Porto Alegre-RS, Brasil
}




\author{
Guilherme Correa Petry \\ Av. Icaraí, 101/202, Bairro Cristal \\ 90810-000 - Porto Alegre-RS, Brasil \\ Jacó Braatz \\ Rua Silva Jardim, 749/301, Bairro Bela Vista \\ 90450-071 - Porto Alegre-RS, Brasil \\ Paolo Mazzoncini Martinez \\ Rua Dr. Schmitz, 645 \\ 95780-000 - Montenegro-RS, Brasil \\ Mariana Ceia Ramos Mariano da Rocha \\ Av. Nilo Peçanha, 450/602 \\ 90470-000 - Porto Alegre-RS, Brasil
}

\begin{abstract}
Population aging and public financing: an analysis of Rio Grande do Sul using a multisectoral model

The economic effects of population ageing are rarely addressed in developing countries. In the Brazilian context, Rio Grande do Sul is one of the states with the higher rates of population ageing. This demographic change modifies the economy's consumption pattern, affecting other related variables. The aim of this paper is to analyze the impact of the demographic changes in consumption taxes revenues in Rio Grande do Sul. To that end, a regional input-output model is used. The results show that the aging population generates a consumption profile that reduces the burden of these taxes on the economy.
\end{abstract}

Keywords: Population aging. Final demand structure. Multi-sector analysis. Tax.

\title{
Resumen
}

Envejecimiento de la población y financiación pública: un análisis de Rio Grande do Sul utilizando un modelo multisectorial

Los efectos económicos del envejecimiento de la población son un tema todavía poco estudiado en los países en desarrollo. En el contexto brasileño, Rio Grande do Sul es uno de los estados con mayores tasas de envejecimiento de la población. Este cambio demográfico altera el perfil de consumo de la economía e influye en otras variables relacionadas. El objetivo de este trabajo es analizar los impactos de los cambios demográficos en la recaudación de los impuestos al consumo en Rio Grande do Sul. Para esto, se utiliza un modelo regional de insumos y productos. Los resultados muestran que el envejecimiento de la población genera un perfil de consumo que reduce la carga de estos impuestos en la economía.

Palabras clave: Envejecimiento de la población. Perfil de consumo. Modelo multisectorial. Impuestos. 


\section{Apêndice}

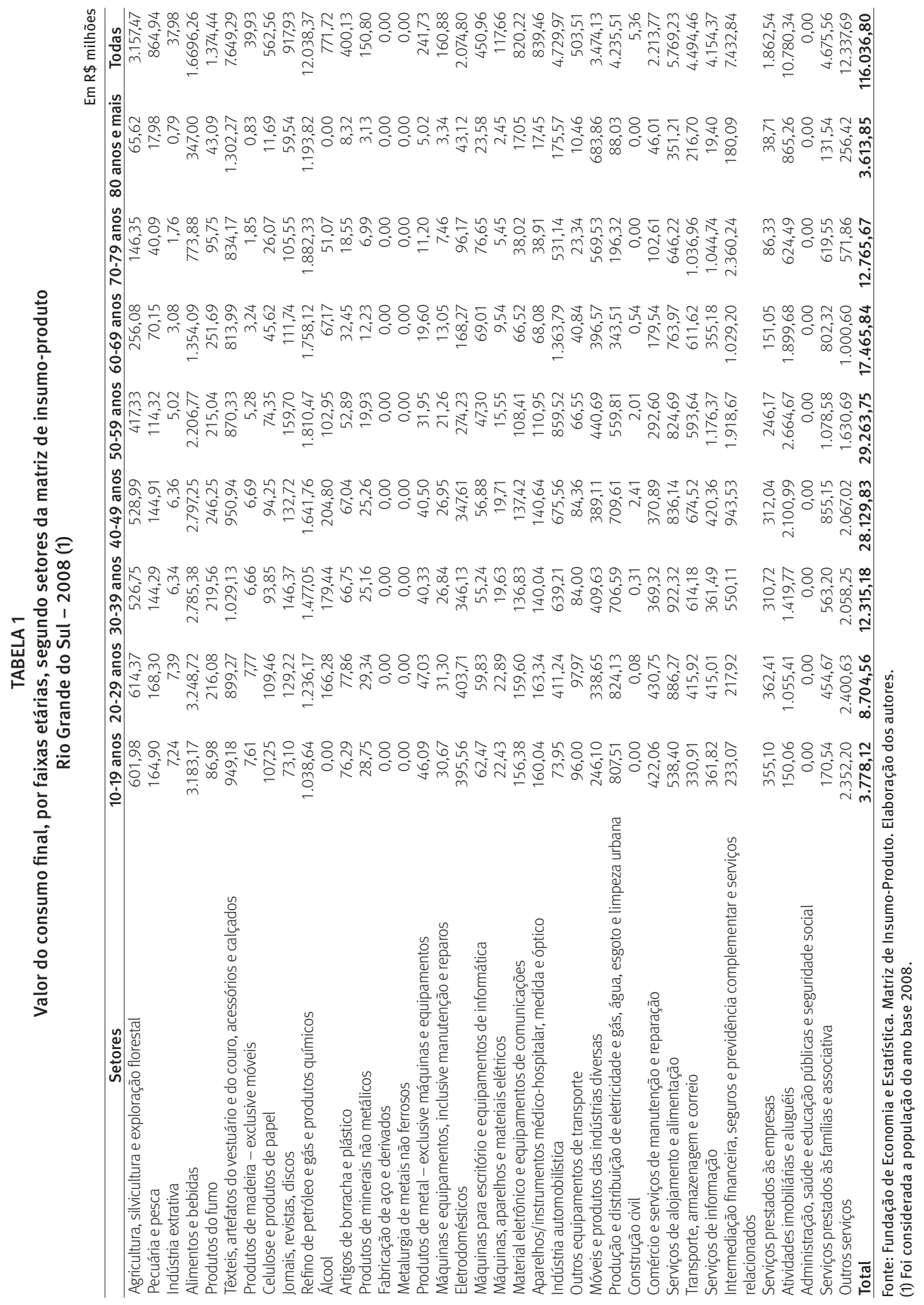




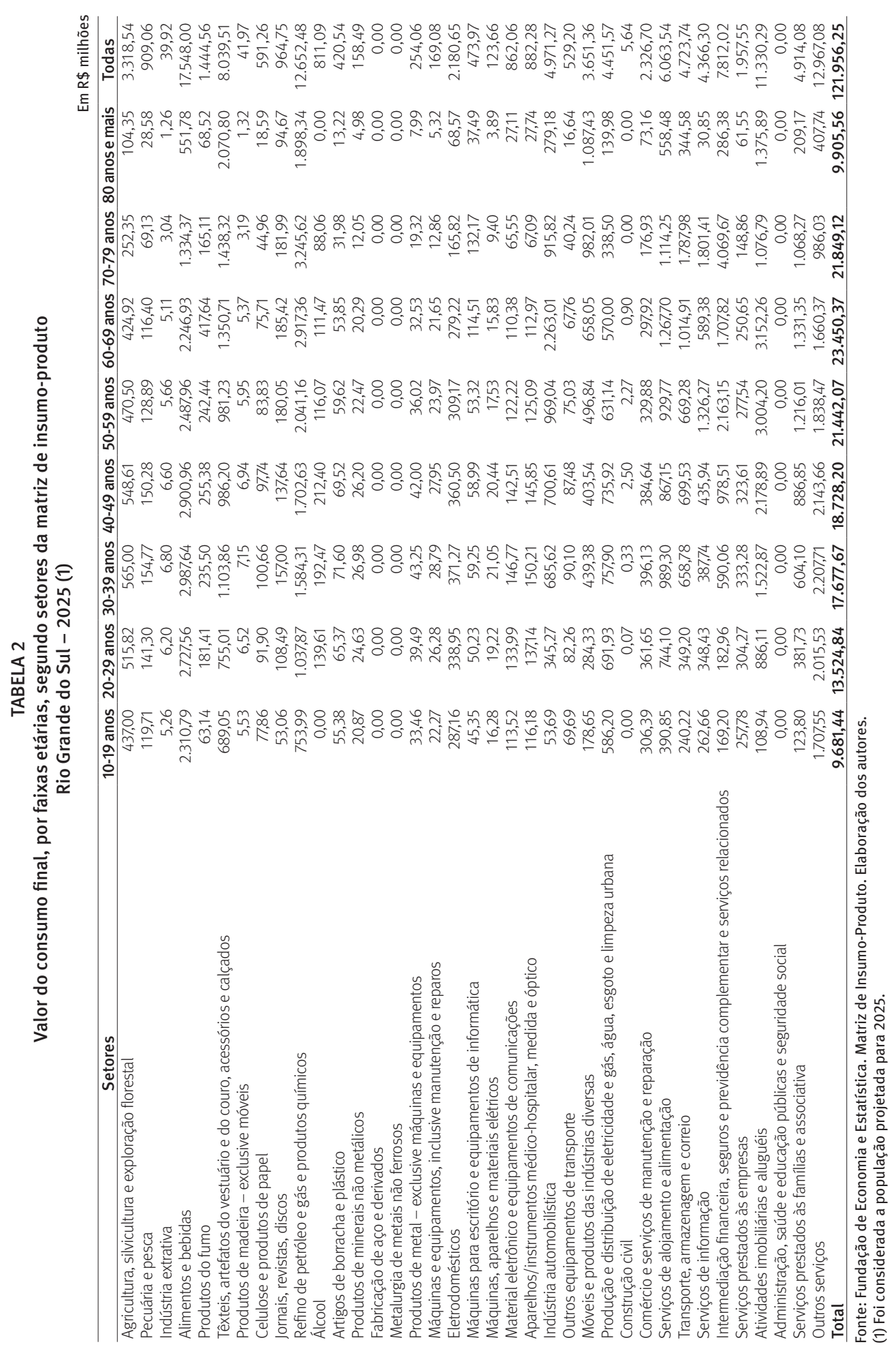




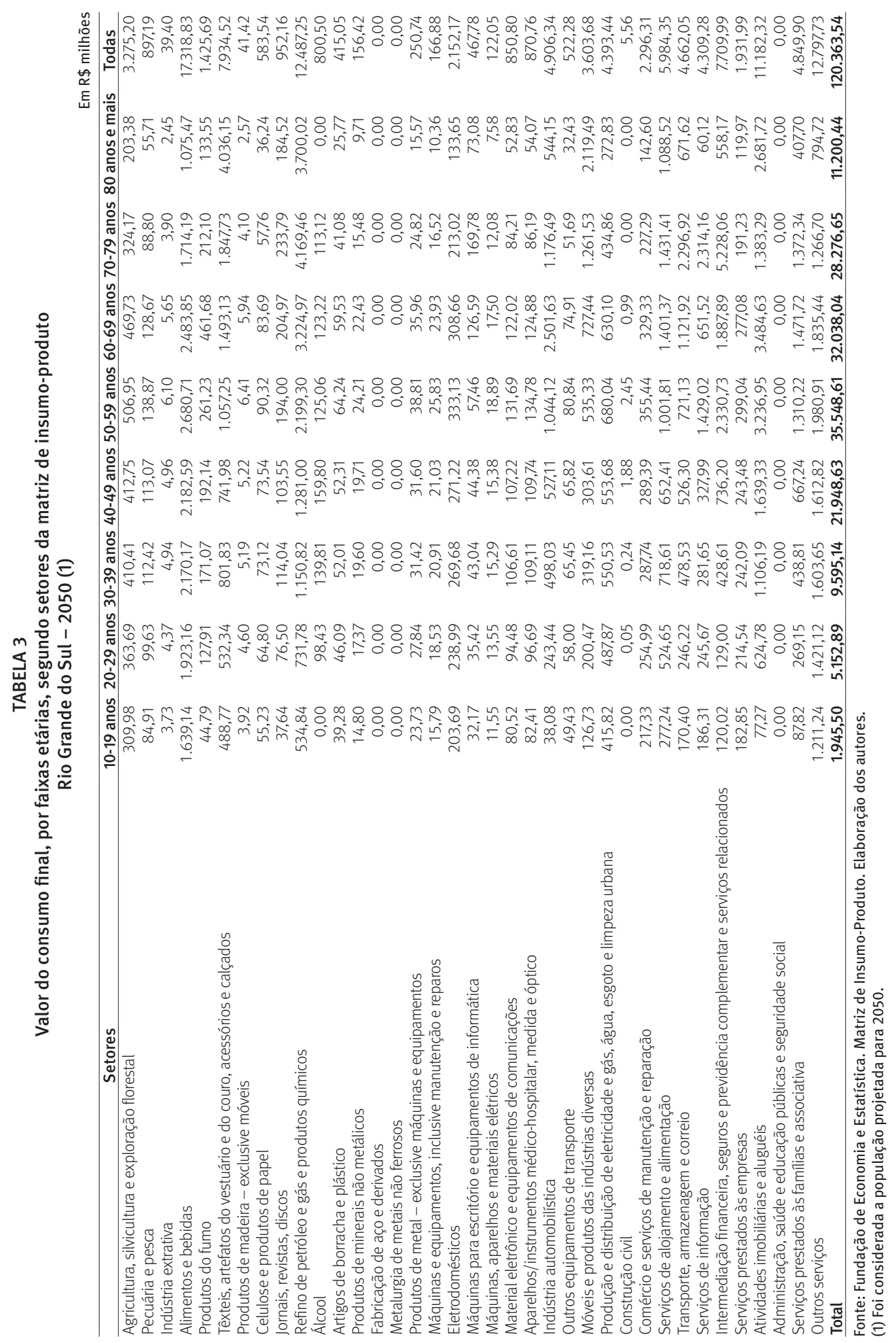




\section{TABELA 4}

Variação da arrecadação de ICMS, segundo setores produtivos Rio Grande do Sul - 2008/2050 (1)

\begin{tabular}{|c|c|c|}
\hline \multirow{2}{*}{ Setores } & \multicolumn{2}{|c|}{ Variação (\%) } \\
\hline & $E-08 / 25$ & E-0850 \\
\hline Agricultura, silvicultura e exploração florestal & 0,867 & 1,923 \\
\hline Pecuária e pesca & 0,747 & 1,720 \\
\hline Indústria extrativa & 2,436 & 5,814 \\
\hline Alimentos e bebidas & 0,723 & 1,704 \\
\hline Produtos do fumo & 2,207 & 3,944 \\
\hline Têxteis, artefatos do vestuário e do couro, acessórios e calçados & 7,087 & 21,645 \\
\hline Produtos de madeira - exclusive móveis & 2,715 & 7,619 \\
\hline Celulose e produtos de papel & 1,496 & 3,683 \\
\hline Jornais, revistas, discos & 6,711 & 14,915 \\
\hline Refino de petróleo e gás e produtos químicos & 5,830 & 14,038 \\
\hline Álcool & 6,039 & 3,538 \\
\hline Artigos de borracha e plástico & 0,711 & 1,591 \\
\hline Produtos de minerais não metálicos & 1,395 & 3,307 \\
\hline Fabricação de aço e derivados & 0,756 & 1,540 \\
\hline Metalurgia de metais não ferrosos & 0,478 & 1,108 \\
\hline Produtos de metal - exclusive máquinas e equipamentos & 0,682 & 1,596 \\
\hline Máquinas e equipamentos, inclusive manutenção e reparos & 0,074 & 0,173 \\
\hline Eletrodomésticos & 0,012 & 0,024 \\
\hline Máquinas para escritório e equipamentos de informática & 1,959 & 4,291 \\
\hline Máquinas, aparelhos e materiais elétricos & 0,529 & 1,161 \\
\hline Material eletrônico e equipamentos de comunicações & 0,141 & 0,300 \\
\hline Aparelhos/instrumentos médico-hospitalar, medida e óptico & 0,091 & 0,189 \\
\hline Indústria automobilística & 3,517 & 6,537 \\
\hline Outros equipamentos de transporte & 0,265 & 0,550 \\
\hline Móveis e produtos das indústrias diversas & 7,030 & 20,203 \\
\hline Produção e distribuição de eletricidade e gás, água, esgoto e limpeza urbana & 1,316 & 3,019 \\
\hline Construção civil & 0,625 & 1,336 \\
\hline Comércio e serviços de manutenção e reparação & 2,771 & 6,629 \\
\hline Serviços de alojamento e alimentação & 10,280 & 22,886 \\
\hline Transporte, armazenagem e correio & 6,910 & 14,717 \\
\hline Serviços de informação & 9,469 & 19,927 \\
\hline Intermediação financeira, seguros e previdência complementar e serviços relacionados & 12,634 & 26,485 \\
\hline Serviços prestados às empresas & 3,258 & 7,035 \\
\hline Atividades imobiliárias e aluguéis & 13,061 & 29,150 \\
\hline Administração, saúde e educação públicas e seguridade social & 0,084 & 0,183 \\
\hline Serviços prestados às famílias e associativa & 9,677 & 18,742 \\
\hline Outros serviços & 0,058 & 0,122 \\
\hline Total dos setores & 3,839 & 8,776 \\
\hline
\end{tabular}

Fonte: Fundação de Economia e Estatística. Matriz de Insumo-Produto. Elaboração dos autores. (1) Foram consideradas as estruturas etárias de 2008, 2025 e 2050 e a população de 2008. 